\title{
Development of Nimbolide from Seeds of Azadirachta Indica Extract Assisted by Molecular Docking to Cyclin E, against Cervical Cancer
}

\author{
Tribhuvan Singh ${ }^{1} *$, Harvinder Singh Saini ${ }^{2}$, S.V. Ranganayakulu ${ }^{2}$, S. Ravi ${ }^{3}$, \\ K. Sudhakar ${ }^{3}$ \\ ${ }^{*}$ *Guru Nanak Institutions Technical Campus - School of Pharmacy \\ Ibrahimpatnam, Hyderabad-501506 \\ ${ }^{2}$ Guru Nanak Institutions Technical Campus - School of Engineering and Technology \\ Ibrahimpatnam, Hyderabad-501506 \\ ${ }^{3}$ Rural Development Society, R\&D Center, Punjagutta, Hyderabad-500082
}

\begin{abstract}
The recent studies on Nimbolide, a robust cervical anticancer agent was identified for the separation of Nimbolide from Azadirachta indica berry collected from Ranga Reddy-Dist, the seeds were initially isolated, dried and transformed into coarse powder. The seed core was defatted and concentrated using methanol in a soxhlet apparatus. The methanolic extract obtained from seeds is subjected to High Performance Liquid Chromatography [HPLC] by direct reverse phase method for isolation of Nimbolide using Molecular Docking of Nimbolide through Molecular Operatin Environment [MOE] 2008 software. This declared that Nimbolide has capability of binding $12.3 \%$ to a Glycine 131 undergoing polar interactions. Nimbolide was found to interact with Cyclin E, was redeemed from the Protein Data Bank [PDB code; 1W98]. It was observed that Nimbolide showed an satisfactory increased life span (54.32 and 65.16), decreased the viable cells $(52.3 \pm 1.5$ and $32.5 \pm 1.3)$, and tumor volume $(3.2 \pm 0.03$ and $2.4 \pm 0.04)$.
\end{abstract}

Keywords: Azadirachta Indica, Cervical Cancer, 5-Fluorouracil, (HeLa) Henrietta Lacks cell line, Molecular Docking, Nimbolide.

\section{Introduction}

The Cervical Cancer is defined as repetitive growth of the tumor at cervical region, the micro invasion of greater than 3 millimeter intensity of stomach to get spread up by metastasis less than 7 millimeter, that prolongs through pelvic sidewall up to the uterus and then further extends into lower third of the vagina. Chemotherapy is a frequently used therapy for cervical cancer medication, in which drugs like 5- fluorouracil, carboplatin, cisplatin, paclitaxel, topotecan, cyclophosphamide, gemcitabine, irinitecan, docetaxel, doxorubicin and mitomycin are used. All the above mentioned drugs have certain toxic side effects. Thus it is necessary for development of natural and safe anticancer agent for the treatment of cervical cancer. In this perspective some phytochemical constituents were distinguished, such as taxol, and vincristine ${ }^{[1]}$. There is increasing number of publications on Azadirachta indica and its extract to fight against cervical cancer. Azadirachta indica is evergreen, tropical, possessing oblique shaped green leaves and trunk of timber with insect repellent properties ${ }^{[2]}$. Roughly speaking, Azadirachta indica showed an anticancer activity by promoting the antioxidant enzyme, and modifying the intracellular components essential for cancer growth and development; such as Cyclin D, Cyclin B, Cyclin B1, Cyclin1, Cyclin E, P53, PCNA, P21,GST-P. Nimbolide was found to interact with the cell cycle kinetics in cancer cells by promoting the cell cycle arrest at G1/S or G2/M phase through suppression of Cyclin, CDKs and PCNA ${ }^{[3,4,5,6]}$. Nimbolide can be extracted from Azadirachta indica kernel powder by using an organic solvent such as ethyl acetate for microwave-assisted extraction, and it is refluxed for $15 \mathrm{hrs}$. 100 grams of Azadirachta indica kernel powder gives near about $1 \mathrm{gm}$ of Nimbolide. The Study of Molecular docking was performed and gave a vision to the interacting mode of Nimbolide by using The Molecular Operating Environment (MOE) 2008 software. Recent studies discovered that Nimbolide has capability of binding $12.3 \%$ to a Glycine 131 with polar interactions. Nimbolide was known to combine with Cyclin E, which causes phosphorylation of cancer cell and stop the G1/S phase protein expression ${ }^{[7]}$.

\subsection{From Azadirachta indica Seeds Extraction of Nimbolide}

\section{Materials And Methods}

Nimbolide is an enhanced concentrate enclosing $60 \%$ active ingredient. The Azadirachta indica berries were obtained from local area then kernels were isolated from fruits. The seeds were dried and made in to coarse powder. The Azadirachta indica kernels were defatted using an organic solvent such as ethyl acetic acid in a dissolvable microwave (Make: Samsung, Model: 2015) by the extraction procedure. By using soxhlet 
apparatus the methanolic extract was prepared (Make: Nsaw, Model: 2016) refluxed for 15 hrs, i.e hot extraction procedure and solvent recovery done by using rotary evaporator, (Make: Aditya, Model: 2015) then the extract was isolated by a recent method i.e. direct application of methanolic extract of kernels of Azadirachta indica in a preparative reverse phase HPLC without using prior column chromatography, (Make: Sigmaaldrich, Model: 2016) to isolate Nimbolide ${ }^{[8]}$.

\subsubsection{Studies which Relates to Molecular Docking}

By using MOE 2008 docking was done. Cyclin E was obtained from PDB and receptor was visualized by sequence option and deletion of cofactors is made. Partial protein charge was adjusted using force field method and building of Assisted Model (AMBER 99) was adjusted using energy refinement. 3D protonation was done at cut off 12.0 and hydrogen was added using standard geometry $0.01 \mathrm{KJ}$ mole gradients Merck Molecular Force Field (MMFF94x) was found after minimization. With the assistance of developer module the ligand structures were framed and with the strategy for Hamilton MMFF94 constrain field fractional charges were balanced and thusly as indicated by standard geometry 3D protonation and hydrogen were included. At $0.01 \mathrm{KJ}$ mole inclination of drive field MMFF94x vitality was minimized to ligands at cut off 12 . By utilizing the choice reenactment docking was performed and it was trailed by dock on the dynamic locales of chose amino acids with the assistance of arrangement alternative and inevitably the settings choices, for example, receptor and dissolvable, chose deposits, drive field refinement, alpha triangle and best 30 represent the docking was finished. From the 30 best postured of every structure of compound in the wake of getting the outcomes the fulfillment of best will be acquire. In the arrangement the best stance of resultant score qualities were utilized for docking examination and collaboration ${ }^{[9]}$.

\subsubsection{Protien Data Bank, Nimbolide of Molecular Docking (PDB Code: 1W98) [Figure 1 and 2].}

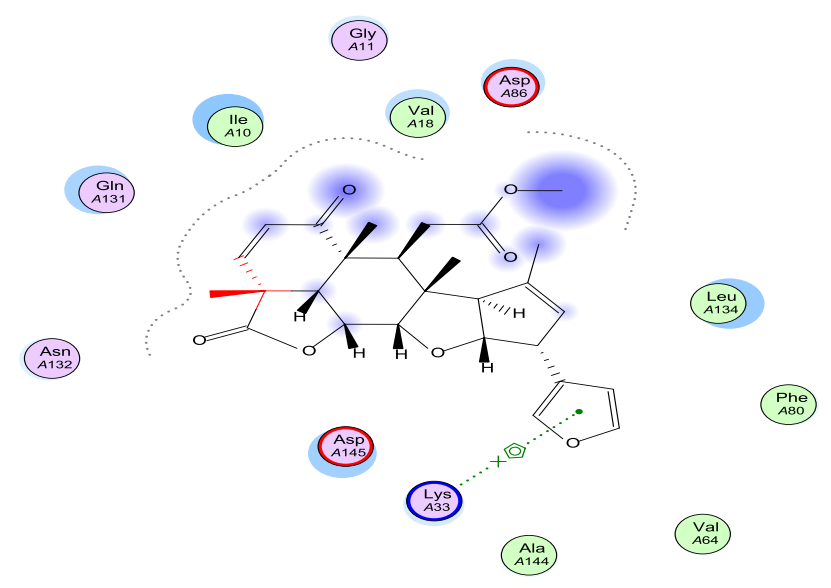

Figure 1: Two-Dimensional Structure Model Interacting Mode of Nimbolide with Cyclin E.

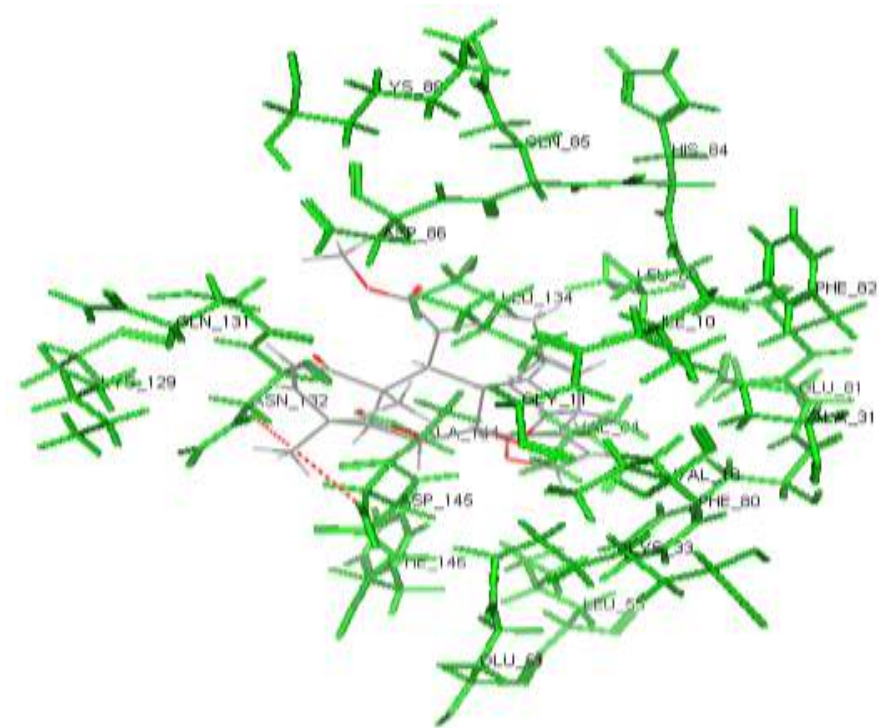

Figure 2: Three-Dimensional Structure Model Interacting Mode of Nimbolide with Cyclin E. 


\subsubsection{Activity of Anticancer}

Institutional Animal ethics committee of Guru Nanak Institute of Pharmacy, Hyderabad, India (Reg no: 1374/air conditioning/10/CPCSEA conducted an experimental protocol on mice for the pharmacological screening. The screening of anticancer activity was conducted on Male Albino Swiss which weighs up to 20-25 g. Under the states of standard lab, Male Albino was kept up with access to water and food not indispensable. Preceding in vivo test for the time of seven days the chosen animals in environment of research facility were permitted to adjust. The animals which were chosen partitioned into 5 batches containing 12 animals each. From the contributor mice HeLa cell lines got and were suspended in a $0.9 \%$ Nacl typical saline. The check of cell was changed in accordance with $2 \times 106$ cells $/ \mathrm{mL}$. Through the intraperitoneal course HeLa cell line were dealt with in all gatherings aside from the ordinary gathering which is in control on day zero. Ordinary saline (5 $\mathrm{mL} / \mathrm{kg}$ body weight) is dealt with in gathering 1 , HeLa cell line in gathering 2 and 5 -flourouracil $(20 \mathrm{mg} / \mathrm{kg}$ body weight) in gathering 3 . At a measurement of 50 and $100 \mathrm{mg} / \mathrm{kg}$ body weight the compound test which has a place with gathering $4 \& 5$ was regulated through intraperitoneal course. After tumor transplantation 5flourouracil and the test compound were dealt with for 9 days. Every gathering of 6 animals was yielded following 9 days. Against Cyclin E the assessment of tumor was finished. For the staying every gathering of 6 mice were recorded for Mean survival time ${ }^{[10,11]}$. [Table1].

Table NO.1

\begin{tabular}{|c|c|c|c|c|c|}
\hline $\begin{array}{c}\text { NO. of } \\
\text { groups }\end{array}$ & Saline & $\begin{array}{c}\text { Name of cancer } \\
\text { cell- line }\end{array}$ & $\begin{array}{c}\text { No. of cancer } \\
\text { cells }\end{array}$ & $\begin{array}{c}\text { Name of } \\
\text { control/standard/ } \\
\text { test }\end{array}$ & mg/ kg/ body weight \\
\hline 1. & $\begin{array}{c}\text { Normal } \\
\text { saline }\end{array}$ & - & - & - & - \\
\hline 2. & - & HeLa & $2 \times 10^{6}$ cells & Control & - \\
\hline 3. & - & HeLa & $2 \times 10^{6}$ cells & 5 -Fluorouracil $(\mathbf{S})$ & $20 \mathrm{mg} / \mathrm{kg}$ body weight \\
\hline 4. & - & HeLa & $2 \times 10^{6}$ cells & Nimbolide $(\mathbf{T})$ & $50 \mathrm{mg} / \mathrm{kg}$ body weight \\
\hline 5. & - & HeLa & $2 \times 10^{6}$ cells & Nimbolide (T) & $100 \mathrm{mg} / \mathrm{kg}$ body weight \\
\hline
\end{tabular}

\subsubsection{Cell Count of Tumor}

The 6 mice were accomplished for the procedure of dissection and from the peritoneal depression the harvestation of aggregate liquid were done. With the assistance of graduated rotator (centrifuge tube) the volume was measured and PCV is noted at $1000 \mathrm{rpm}$ for 5 minutes. Exclusion test was done by using trypan blue color dye to check feasible cells which were counted in Neubauers counting chamber ${ }^{[12,13]}$

\subsubsection{Increase Life Span \% and Mean Survival Time}

On tumor development the Nimbolide movement was assessed and mortality recording is done inside the perception time frame. By utilizing formula the life expectancy in $\%$ was computed ${ }^{[14,15,16]}$

Percentage ILS $=$ MST of treated group - MST of control group $\times 100$ MST of control group

Mean Survival Time $\quad=$ Survival time of each mice in a group in days

\section{Total number of mice}

\section{Results And Discussion}

The investigation of docking test was done on windows 2007 utilizing MOE 2008. From the protein data bank(PDB code: 1W98), the Cyclin E was recovered, current reviews uncovered that Nimbolide has a liking of $59.2 \%$ and $72 \%$ towards amino acids like Glycine 131 and Lysine 89 with polar communications. Nimbolide known to connect with Cyclin E and causes phosphorylation, inhibits the protein expression of G1/S. The test samples were kept as standard and Nimbolide $(50$ and $100 \mathrm{mg} / \mathrm{kg}$ body weight from the estimations of diminishing in tumor cell check, \% ILS 5-fluorouracil ( $20 \mathrm{mg} / \mathrm{kg}$ body weight) and MST. The outcomes were appeared in [Table2]. The action of antitumor of tried Nimbolide on HeLa cell line in vivo ponders relies on upon no.of feasible cells and tumor volume. In cell number and tumor volume the Nimbolide significancantly showed in reduction when contrasted with control. The Nimbolide demonstrated satisfactory \%ILS (54.32 and 65.16), decreased the reasonable cells $(52.3 \pm 1.5$ and $32.5 \pm 1.3)$, and tumor volume $(3.2 \pm 0.03$ and $2.4 \pm 0.04)$ separately as contrasted and 5-Fluorouracil. The Nimbolide demonstrated a superb collaboration in docking of atom and the cervical anticancer direction were given. The amino acids, for example, Asp-A86, Ile-A10, GlyA131, Asn-A132, Asp-A145 communicate with Cyclin E at the dynamic site. Gly-A 131 with the official Nimbolide has capability of binding $12.3 \%$ to a Glycine 131 undergoing polar interactions. 
Development of Nimbolide from Seeds of Azadirachta Indica Extract Assisted by Molecular Docking..

Table No.2: In Vivo Antiproliferative Activity of Nimbolide against (HeLa) Cell line

\begin{tabular}{|c|c|c|c|c|}
\hline $\begin{array}{c}\text { No. of } \\
\text { groups }\end{array}$ & $\begin{array}{c}\text { Mean Survival Time } \\
(\mathbf{M S T}) \pm \text { SE }\end{array}$ & $\begin{array}{c}\text { IncreaseLife Span } \\
\text { (ILS) (\%) }\end{array}$ & $\begin{array}{c}\text { Tumor Volume (TV) } \\
(\mathbf{m l})\end{array}$ & $\begin{array}{c}\text { Viable Cells } \\
(\text { VC) }(\boldsymbol{\%})\end{array}$ \\
\hline $\mathbf{1 .}$ & - & - & - & - \\
\hline $\mathbf{2 .}$ & $18.5 \pm 0.23$ & - & $3.4 \pm 0.2$ & $94.5 \pm 3.6$ \\
\hline $\mathbf{3 .}$ & $36.6 \pm 0.48$ & 97.83 & $0.9 \pm 0.02$ & $18.1 \pm 1.8$ \\
\hline $\mathbf{4 .}$ & $19.5 \pm 0.52$ & 54.32 & $3.2 \pm 0.03$ & $52.3 \pm 1.4$ \\
\hline $\mathbf{5 .}$ & $27.3+0.34$ & 65.16 & $2.4 \pm 0.04$ & $32.5 \pm 1.3$ \\
\hline
\end{tabular}

\section{Conclusion}

In the present study anticancer activity of Nimbolide was performed in vivo. Compared to standard drug 5-Fluorouracil the Nimbolide was found to have potent anticancer activity. Moreover, the Nimbolide demonstrated huge docking communication with Cyclin E, dynamic site utilizing windows 2002, MOE 2008 programming. Result demonstrated that Nimbolide may prompt to powerful cervical anticancer agent.

\section{Acknowledgements}

I, Dr. Tribhuvan Singh, thankful to Sardar G.S Kohli, Vice Chairman, Guru Nanak Institutions Technical Campus, Hyderabad, to carry out the research work for providing necessary facilities.

\section{Reference}

[1]. Salehzadesh A, Akhkha A, Cushley W, Adams RLP, Kusel JR, and Strang RCH, The antimitotic effect of the neem terpenoid azadirachtin on cultured insect cells Insect, Biochemistry Molecular Biology, 33(7), 2003, 681-689.

[2]. Subapriya R, and Nagini S, Ethanolic neem leaf extract protects against N-methyl-N'-nitro-N-nitrosoguanidine-induced gastric carcinogenesis in Wistar rats, Asian Pacific Journal of Cancer Prevention, (4), 2005, 215-223.

[3]. Subapriya R., Kumaraguruparan R, and Nagini S, Expression of PCNA, cytokeratin, Bcl-2 and p53 during chemoprevention of hamster buccal pouch carcinogenesis by ethanolic neem (Azadirachta indica) leaf extract, Clinical Biochemistry, (39), 2006, 10801087.

[4]. Harish K. G, Chandra Mohan K.V.P, Jagannadha R. A, and Nagini S, Azadirachtin a limonoid from Azadirachta indica inhibits proliferation and induces apoptosis of human choriocarcinoma (BeWo) cells, Invention New Drugs, (27), 2009, 236-252.

[5]. Nagini S, Bhuvaneswari V, and Subapriya R., Ethanolic neem leaf extract induces apoptosis in the hamster buccal pouch carcinogenesis model by modulation of BCL-2, BIM, caspase 8 and caspase 3, Asian Pacific Journal of Cancer Prevention, (6), 2005, 515-520

[6]. Veeraraghavan J, Aravindan S, Natarajan M, Awasthi V, Herman T.S, and Aravindan N, Neem leaf extract induces radio sensitization in human neuroblastoma xenograft through modulation of apoptotic pathway. Anticancer Research, 31(1), 2011, 161170.

[7]. Garofalo A, Goossens L, Six P, Lemoine A, Ravez S, and FarceA, Impact of aryloxy-linked quinazolines: A novel series of selective VEGFR-2 receptor tyrosine kinase inhibitors, Bioorganic and Medicinal Chemistry Letters, (21), 2011, 2106-2112.

[8]. Deota P. T, Upadhyay P. R, Patel K. B, Mehta K. J, Kamath B. V, and Mehta M. H, Estimation and isolation of azadirichitin A from neem (Azadirachta indica) seed kernels using HPLC, Journal of Liquid Chromatography and Related Technology, 23(14), 2007, 2225-2235.

[9]. Dhamija I, Kumar N, Manjula S.N, Parihar V, Setty M. M, and Pai KS, Preliminary evaluation of in vitro cytotoxicity and in vivo antitumor activity of premna herbacea roxb in ehrlich ascites carcinoma model and Daltons lymphoma ascites model, Experimental and Toxicological Pathology, (65), 2013, 235-242.

[10]. Parameshwar R, Vamaraju H. B, Paturi M, Narendra S. C, and Kolli S, Design synthesis in silico toxicity prediction molecular docking and evaluation of novel pyrazole derivatives as potential antiproliferative agents, Excli Journal, (15), 2016,187-202.

[11]. Fatheya M,. and Hatem A. E. M, Antitumor effect of azadirachta indica(neem) on murine solid ehrlich carcinoma, Academic Journal of Cancer Research, 7(1), 2014, 38-45.

[12]. Roy M. K, Kobori M, and Takenaka M, Inhibition of colon cancer (HT-29) cell proliferation by a triterpenoid isolated from Azadirachta indica is accompanied by cell cycle arrest and upregulation of p21, Planta Medica, (72), 2006, 917-923.

[13]. Vidya Priyadarsini R, Manikandan P, Harish Kumar G, and Nagini S, The neem limonoids azadirachtin and nimbolide inhibit hamster cheek pouch carcinogenesis by modulating xenobiotic-metabolizing enzymes, DNA damage, antioxidants, invasion, an angiogenesis, Free Radical Research, (43), 2009, 492-504.

[14]. Tepsuwan A, Kupradinun P, and Kusamaran W. R, Chemopreventive potential of neem flowers on carcinogenesis induced rat mammary and liver carcinogenesis, Asian Pacific Journal of Cancer (3), 2002, 231-238.

[15]. Paul R, Prasad M, and Sah N. K, Anticancer biology of Azadirachta indica (neem), Cancer Biology. Therapy, 12(6), 2011, 467476.

[16]. Akihisa T, Cytotoxic, and apoptosis- inducing activity of limonoids from the seeds of azadirachta indica (Neem), Journal of Natural Products, (74), 2011, 866-870 